\title{
Removal of ions from produced water using Powder River Basin coal
}

\author{
Zaixing Huang ${ }^{1} \cdot$ Fangjing $\mathrm{Liu}^{2} \cdot$ Mingchen Tang $^{2} \cdot$ Yangyan Gao $^{2,3} \cdot$ David M. Bagley $^{2} \cdot$ Xin $\mathrm{He}^{2}$. \\ Alexander Goroncy ${ }^{4} \cdot$ Maohong Fan ${ }^{1,5}$ (1)
}

Received: 4 August 2021 / Accepted: 17 January 2022

(c) The Author(s) 2022

\begin{abstract}
In addition to being used as an energy source, coal also has significant potential for other, more sustainable uses including water treatment. In this study, we present a simple approach to treat water that was produced during oil production and contained a total dissolved solids (TDS) content of over $150 \mathrm{~g} / \mathrm{L}$ using Powder River Basin (PRB) coal. PRB coal used as packing material in a flow-through column effectively removed $60 \%-80 \%$ of the cations and anions simultaneously. Additionally, $71 \%-92 \%$ of the total organic carbon in the produced water was removed as was all of the total suspended solids. The removal mechanisms of both cations and anions were investigated. Cations were removed by ion exchange with protons from oxygen-containing functional groups such as carboxylic and phenolic hydroxyl groups. Anions, mainly $\mathrm{Cl}^{-1}$, appeared to be removed through either the formation of resonance structures as a result of delocalization of electrons within coal molecules or through ion- $\pi$ interactions. We propose that coal is a "pseudo-amphoteric" exchange material that can remove cations and anions simultaneously by exchanging ions with both ionized and non-ionized acids that are ubiquitous in coal structure or resonance effect.
\end{abstract}

\section{Graphical abstract}

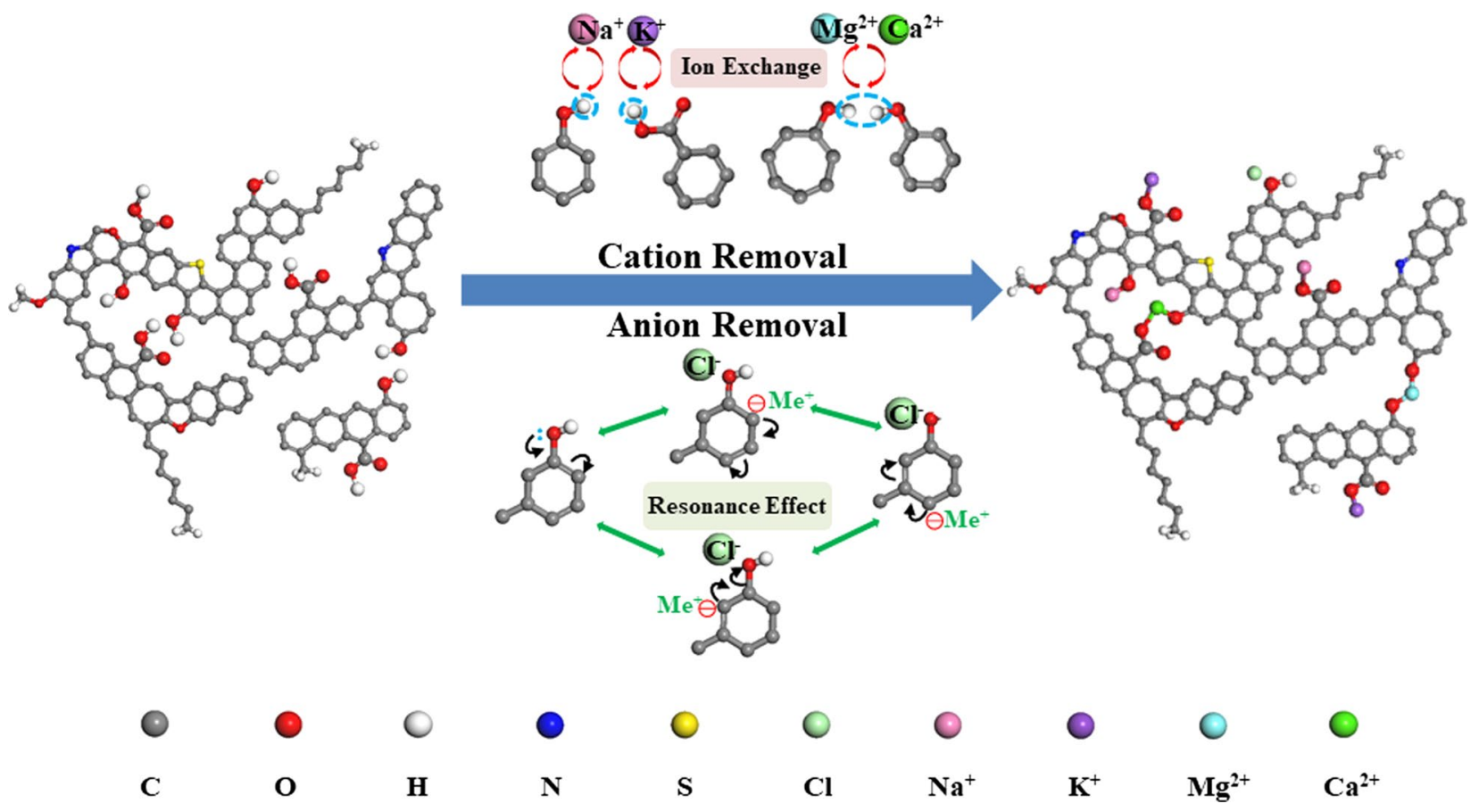

Keywords Produced water $\cdot$ Ion exchange $\cdot$ Resonance effect $\cdot$ Ion $-\pi$ interaction $\cdot$ Sustainability

Extended author information available on the last page of the article 


\section{Introduction}

Global population growth and climate change have made sustainable water supply a challenge to all human beings. Hoekstra estimated that 2 billion people are living in areas with severe water scarcity (Hoekstra 2014). The same author updated the number to 4 billion in a later model (Mekonnen and Hoekstra 2016). Yet "produced water" is produced in large quantities concurrently with oil production, gas production, and other unconventional oil and gas production including coalbed methane and shale oil and gas extraction (Stoll et al. 2015; Veil et al. 2004; Vengosh et al. 2014). The water-to-oil ratio for oil production is about 3:1 (SPE). The oil and gas industries produce about 14.5 billion $\mathrm{m}^{3} /$ year (250 million barrels/day) of produced water, of which $40 \%$ is discharged into the environment (Fakhru'l-Razi et al. 2009). Produced water accounts for more than $80 \%$ of the liquid waste (Igunnu and Chen 2014) produced during oil and gas production.

Although a significant potential source of water, produced water contains organic and inorganic compounds. Specifically, dissolved and dispersed oils (BTEX, PAHs, and phenols), grease, heavy metals, radionuclides, treating chemicals, formation solids, salts, dissolved gases, scale products, waxes, microorganisms, and dissolved oxygen are commonly found in produced water. Furthermore, the treatment and disposal of produced water are costly. The expense for treating this potential resource is estimated at $\$ 40$ billion per year (SPE) while the disposal cost on a unit basis could be as high as $\$ 4 /$ barrel, depending on the quality of the produced water and the methods that are used (Duraisamy et al. 2013).

Nevertheless, due to the need for water and the desire to limit environmental damage due to discharge, treatment of produced water for potable and irrigation uses has become an option (Qi et al. 2021). Conventionally, produced water is disposed of direct discharge or reinjection into disposal wells (Duraisamy et al. 2013; Jiménez et al. 2018), thus providing no beneficial use of the water. Physical treatment processes include adsorption, sand filters, hydrocyclones, evaporation, dissolved air precipitation, C-TOUR, freeze-thaw evaporation, devaporation, electrodialysis/ electrodialysis reversal, gas flotation, and macro-porous polymer extraction. Chemical treatment processes include chemical precipitation, chemical oxidation, electrochemical processes, photocatalytic treatment, in situ chemical oxidation (ISCO), room temperature ionic liquid, and demulsifier (Dickhout et al. 2017; Duraisamy et al. 2013; Fakhru'l-Razi et al. 2009; Igunnu and Chen 2014; Li et al. 2010; Munirasu et al. 2016). Membrane filtration, using microfiltration, ultrafiltration, reverse osmosis, nanofiltration, bentonite clay, and zeolite membrane technologies (Dickhout et al. 2017; Munirasu et al. 2016; Nasiri et al. 2017), has been extensively examined with emerging produced water treatment technologies including membrane distillation (Woo et al. 2017), forward osmosis (Bell et al. 2017), and the two combined (Kim et al. 2017). However, membrane fouling and high capital and operational costs remain a big hurdle for these membrane filtration technologies (Duraisamy et al. 2013; Stoll et al. 2015). Hackney and Wiesner (1996) estimated the cost for treating average quality produced water to remove most of the solids, organic, and inorganic components with unit processes to be $\$ 8.06 / \mathrm{m}^{3}$ adjusted to the inflation rate of 2019 and increasing up to $\$ 35.00 / \mathrm{m}^{3}$ for produced water having high concentrations of organic constituents, total suspended solids (TSS), and total dissolved solids (TDS), with TDS removal dominating the cost.

Another fossil fuel, coal, may have the potential for costeffectively treating produced water from other fossil fuel production processes. Coal accounting for over $88 \%$ of the worlds' fossil fuels (Wang et al. 2019), is widely available and found in about 100 countries all over the world (Andruleit et al. 2016) and is predicted to outlast other hydrocarbon resources by hundreds of years. Furthermore, the conventional uses of coal for power generation, steel making, and chemical feedstock production (Falbe et al. 1982) are becoming less attractive because these uses produce pollutants and emit more $\mathrm{CO}_{2}$ than any other energy sources (Huang et al. 2017). Coal is now being examined as an inexpensive raw material for manufacturing activated carbon (Rosa et al. 2017), carbon fiber (Li et al. 2017; Liu et al. 2018), silicon metal (WCA), and sorbent (virus removal from water) (Oza and Chaudhuri 1975), for example. Other studies have examined using coal fly ash for synthesizing zeolites (Otal et al. 2005; Querol et al. 2002) or ceramic microfiltration membrane (Jedidi et al. 2009) to be used for produced water treatment. Song et al. reported the fabrication of a microfiltration carbon membrane with anthracite to remove oil from oily wastewater (Song et al. 2006). The preparation required carbonization of the coal at an elevated temperature for up to $900{ }^{\circ} \mathrm{C}$. Sulfonated or ammoniated coal was prepared with chemical reactions to add additional functional groups to enhance the ion exchange capacity of coal (Nachod 2012).

These uses require processing of coal in some manner prior to use. Yet coal is a complex material that may have inherent properties suitable for treating produced water directly, without extensive processing of the coal. The objectives of this work were (i) to test the hypothesis that native subbituminous coal from Wyoming's Powder River Basin can effectively treat produced water by removing extremely high concentrations of TDS as well as organic carbon, and suspended solids simultaneously, and (ii) to evaluate the ion exchange and sorption mechanisms by which cations and anions are removed. To the best of our knowledge, this is the first work to investigate the treatment of produced water with 
native coal directly for simultaneous removal of suspended solids, organic, and inorganic components.

\section{Materials and methods}

\subsection{Coal and produced water}

Powder River Basin coal from Wyodak was provided by Black Hills Corporation. Coal was milled by Wyoming Analytical Lab (Laramie, WY, USA). The fraction of coal with particle sizes between 40 and 60 mesh was used for column preparation. The raw coal contained $16.00 \%$ moisture, $8.18 \%$ ash on a moisture-free basis, and $48.73 \%$ volatile matter on a dry and ash-free basis. The elemental composition of the coal was $78.87 \% \mathrm{C}, 3.72 \% \mathrm{H}, 1.01 \% \mathrm{~N}$, and $15.93 \% \mathrm{O}$ on a dry and ash-free basis (Liu et al. 2018). The pore properties of the coal were BET specific surface area $\left(\mathrm{N}_{2}\right.$ at $\left.77 \mathrm{~K}\right)$ $2.598 \mathrm{~m}^{2} / \mathrm{g}$, DFT pore diameter $0.844 \mathrm{~nm}$, average pore diameter $13.64 \mathrm{~nm}$, and total pore volume $0.018 \mathrm{~cm}^{3} / \mathrm{g}(\mathrm{Xu}$ et al. 2020; Zhang et al. 2021).

The petroleum produced water was provided by Hunt Oil Co. (Knox City, TX, USA). It was collected on February 22, 2018 from the feed before entering the wastewater treatment plant. Key parameters of the produced water included: $\mathrm{pH}$ 6.83, TSS $233 \mathrm{mg} / \mathrm{L}$, TDS $152,320 \mathrm{mg} / \mathrm{L}$, conductivity 238 $\mathrm{mS} / \mathrm{cm}$, total organic carbon (TOC) $42 \mathrm{mg} / \mathrm{L}$, and alkalinity $80 \mathrm{mg} / \mathrm{L}$.

\subsection{Experimental design and operation}

All experiments were conducted by passing produced water through a column packed with coal. A 500-mm long, 25-mm ID Kontes chromatography column equipped with a PTFE stopcock plug (Kimble Chase, Rockwood, TN, USA) was packed with ground coal $(30 \mathrm{~g})$. A pinch of cotton was used as a strainer right before the stopcock plug to strain the coal particles. The coal was washed with 100-mL of deionized (DI) water that was passed through the packed coal by gravity. The final height of packed coal was approximately $65 \mathrm{~mm}$.

Filtration experiments were conducted to examine the removal of suspended solids, organic, and inorganic compounds from produced water. An aliquot of $30 \mathrm{~mL}$ produced water was filtered (by gravity unless otherwise stated) through the column packed with coal. The filtrate was collected and designated as the sample to be analyzed for that cycle. Then the column was washed with $30 \mathrm{~mL}$ of $1 \% \mathrm{HCl}$ (wt/vol, 37\% TraceMetal Grade, Fisher Scientific, Pittsburgh, PA, USA), followed by a DI water rinse until the $\mathrm{pH}$ of the wash was circumneutral. After washing, another 30-mL aliquot of produced water was filtered through the same coal column. This filtration-washing cycle was repeated 10 times.
To investigate the impact of functional groups on the water treatment, the coal was extracted with solvents including NMP (N-Methyl-2-pyrrolidone), THF (tetrahydrofuran), and methanol before being placed in the column. The ground coal was soaked in solvent at a ratio of 1 to 3 (coal wt/solvent wt) at ambient temperature for one week. The coal-solvent mixture was then filtered through a filter paper (Whatman qualitative, Grade 1, GE, Pittsburg, PA) and the coal was washed with that solvent until the filtrate contained no color. The coal was recovered and dried at $80^{\circ} \mathrm{C}$. The dried, extracted coal was then used in the filtration apparatus as described for the sequential filtration experiments.

\subsection{Analytical measurements}

Conductivity, TDS and $\mathrm{pH}$ were measured by an $\mathrm{H} 280 \mathrm{G} \mathrm{pH}$, conductivity and DO meter (Hach, Longmont, CO, USA). The alkalinity measurement was done with an alkalinity test kit AL-AP MG-L (Hach, Longmont, CO, USA). TOC was measured for both raw and treated produced water. TOC was analyzed with a Shimadzu TOC analyzer (TOC V CSN, Shimadzu Corporation, Kyoto, Japan).

The concentrations of major inorganic elements, including $\mathrm{Ca}, \mathrm{Cl}, \mathrm{Fe}, \mathrm{K}, \mathrm{Mg}$, and $\mathrm{Na}$ of the raw and treated produced water were determined by a Perkin Elmer NexIon 300 ICP/MS (Waltham, MA, USA) under standard mode (Huang et al. 2020; Lewińska-Preis et al. 2021). The certified ICP/ MS standards were purchased from Inorganic Ventures (Christiansburg, VA, USA). A Re solution (50 ppb) was used as the internal standard. The water samples were diluted to meet the requirements of the device prior to analysis.

The untreated and solvent-extracted coal were characterized by a Fourier transform infrared (FTIR) spectrometer (Nicolet iS50, Thermo Scientific, USA). The attenuated total reflectance (ATR) technique was used to acquire data without complicated sample preparations. The samples were scanned between 4000 and $400 \mathrm{~cm}^{-1}$ at a resolution of $4 \mathrm{~cm}^{-1}$. The data of each spectrum were collected with 128 scans. Coal samples after filtration and after acid wash were studied using a Scanning Electron Microscopy with Energy Dispersive X-Ray Spectroscopy (SEM-EDS, Model \#51-XMX0005, FEI, Quanta FEG MK2; Oxford Instruments America, USA) to examine the adsorption of the inorganic ions. The coal samples were dried at $80{ }^{\circ} \mathrm{C}$ and spread evenly on a double-sided carbon tape which was then mounted on an SEM stub. The scanning was operated in $\mathrm{HV}$ mode with an accelerating voltage of $20 \mathrm{kV}$. Magic angle spinning nuclear magnetic resonance (MAS-NMR) data were acquired on a Bruker Avance III 600 NMR spectrometer, operating at Larmor frequencies of $600.2 \mathrm{MHz}$ $\left({ }^{1} \mathrm{H}\right), 150.9 \mathrm{MHz}\left({ }^{13} \mathrm{C}\right)$. A $5.0 \mathrm{~mm}$ triple resonance $\left({ }^{1} \mathrm{H},{ }^{13} \mathrm{C}\right.$, $\left.{ }^{15} \mathrm{~N}\right)$ E-free CPMAS Bio-solids probe was used. The temperature was held constant at 25.0 Degree Celsius and the 


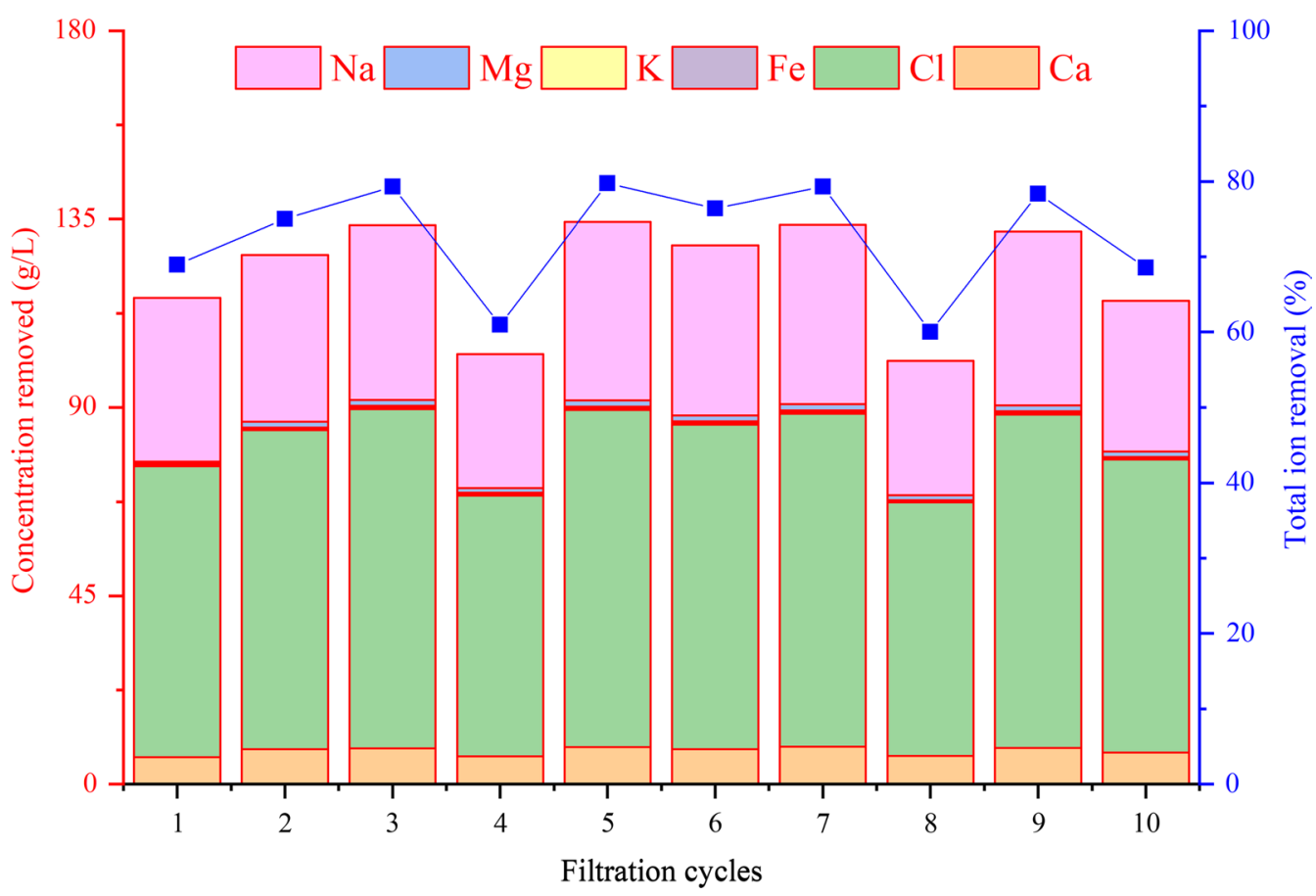

Fig. 1 Inorganic ions removed by filtering 30-mL of produced water through $30 \mathrm{~g}$ of coal. Cycles $2-10$ were conducted with washed (regenerated) coal as described in the text. The raw produced water had TDS of $152 \mathrm{~g} / \mathrm{L}$

spinning rate was $8000 \mathrm{~Hz}$. Calibration was done using $\mathrm{KBr}$ and adamantane. About $30 \mathrm{mg}$ of each sample was measured within $4 \mathrm{~mm} \mathrm{ZrO}_{2}$ rotors. ${ }^{13} \mathrm{C}$-NMR spectra were acquired using cross-polarization (CP), spectral width $=552.1 \mathrm{ppm}$, contact time $=2000 \mu \mathrm{s}$, ramp. 100 and tppm 13 for ${ }^{1} \mathrm{H}$, recycle delay $=2 \mathrm{~s}, 40,960$ scans.

\section{Results and discussion}

\subsection{Removal of inorganic ions, TOC and TSS}

The primary inorganic components of the untreated produced water include cations: $\mathrm{Na}(49.2 \mathrm{~g} / \mathrm{L}), \mathrm{Ca}(10.0 \mathrm{~g} / \mathrm{L})$, $\mathrm{Mg}(1.70 \mathrm{~g} / \mathrm{L}), \mathrm{K}(0.31 \mathrm{~g} / \mathrm{L})$, and Fe $(0.56 \mathrm{~g} / \mathrm{L})$, and an anion: $\mathrm{Cl}(90.8 \mathrm{~g} / \mathrm{L})$. $\mathrm{Na}$ and $\mathrm{Cl}$ comprised about $92 \%$ by weight of the total inorganic ions determined by ICP-MS. These inorganic ions were effectively removed by filtration through the coal column (Fig. 1, Table S1). Ten filtrationregeneration cycles were conducted and showed $60 \%-80 \%$ removal of individual ions with an average removal of $73 \%$. Interestingly, the percent overall removal of all ions was similar, ranging between $64 \%$ and $76 \%$, suggesting there was no specific removal selectivity of these ions. An average of about $0.12 \mathrm{~g}$ of TDS was removed per $\mathrm{g}$ coal for each filtration-regeneration cycle, although there is residual water in the pores of the packed column after washing. There may be dilution effects from the residual water that need further investigation.

Other minerals like bentonite clay and zeolite were also investigated for treating produced water. Bentonite was used as a pretreatment measure and exhibited enhancement of membrane performance in treating produced water (Kusworo et al. 2018; Shahruddin et al. 2015). However, in another study, membrane prepared from bentonite was found to be not effective to treat produced water with high TDS (Li et al. 2003). Zeolite was used to manufacture ion exchange resin/sorbent to remove cations and anions present in water (Jiménez et al. 2018). Studies showed that natural or modified zeolite was able to remove hardness and sodium in produced water (Belbase et al. 2013; Zhao et al. 2008, 2009). However, major applications of zeolite in produced water treatment focus on the removal of organic components such as benzene, toluene, ethylbenzene, and xylenes (BTEX) compounds (Ranck et al. 2005).

The TOC concentration of the original produced water was $42 \mathrm{mg} / \mathrm{L}$. During filtration through the coal column, $71 \%-92 \%$ of the TOC was removed. The removal efficiency of the initial cycle (Cycle-1) was the lowest (71\%), whereas the mean value of the remaining 9 cycles was $90 \%$. The removal capacity of organic components was significantly improved after coal regenerations. However, a pretreatment may be needed to remove dispersed and/or dissolved oil if the concentration is high, because an oil film can be formed and reduce the effective sites for ion removal. The TSS was 

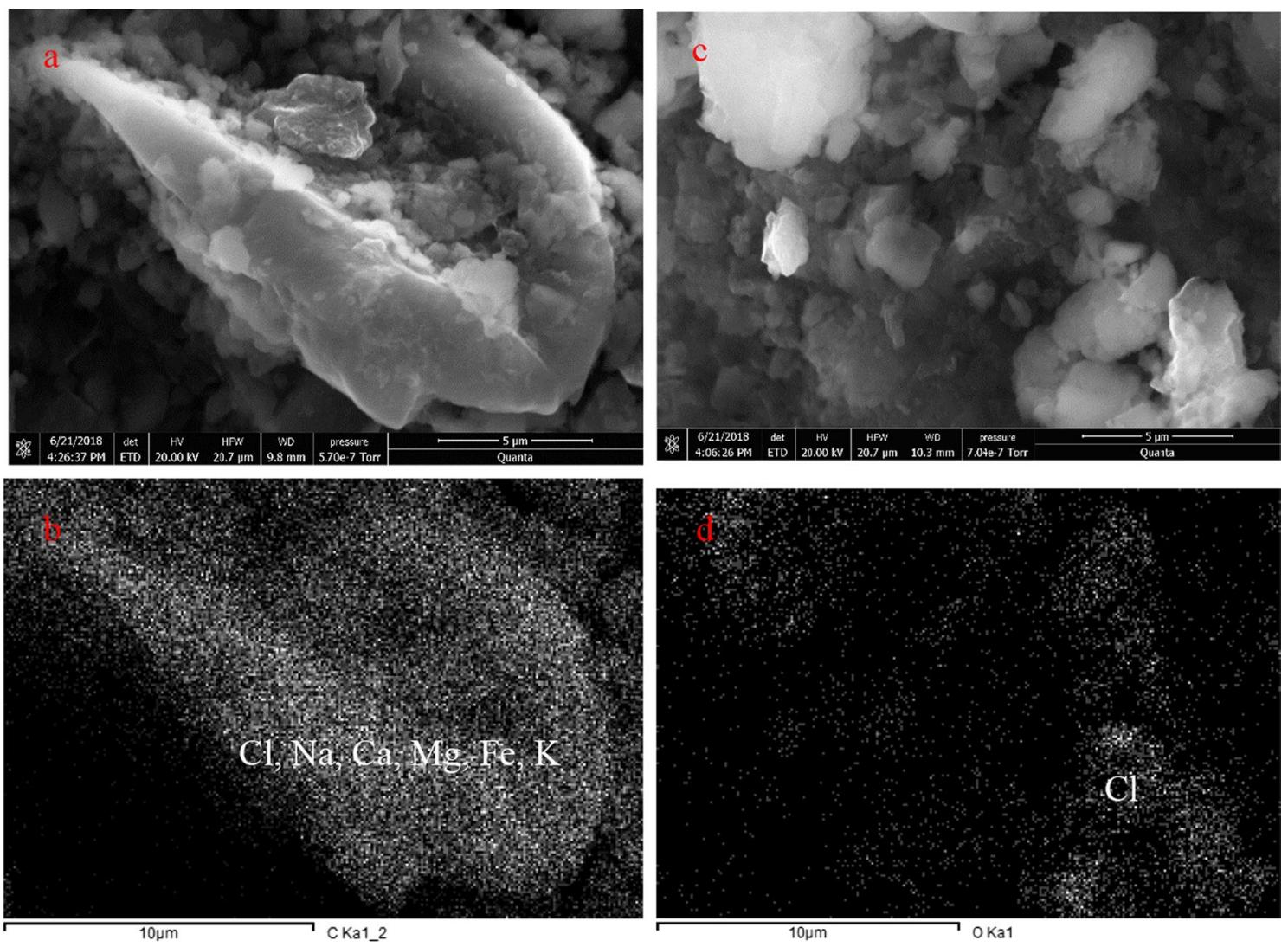

Fig. 2 SEM \& EDS images of the coal samples. a SEM of coal directly after filtration; $\mathbf{b}$ EDS of coal directly after filtration; $\mathbf{c}$ SEM of coal after regeneration with acid wash; d EDS of coal after regeneration with acid wash

decreased from $233 \mathrm{mg} / \mathrm{L}$ in the raw produced water to a negligible level (below detection) in the filtrate.

Figure 2 shows SEM and EDS images of the coal samples directly after filtration and also after regeneration with the acid wash. The EDS analysis (Fig. 2b) clearly shows adsorption/deposition of major inorganic ions on the surface of coal particles. After regeneration with the acid wash, most of the cations were removed (Fig. 2d), thus confirming how the treatment cycles worked. Ions were retained in the coal through filtration and subsequently removed by acid wash, thereby regenerating the coal medium for further filtration cycles. After regeneration with the acid wash, $\mathrm{Cl}$ dominated the surface of coal (Fig. 2d) because diluted $\mathrm{HCl}$ solution was used as the washing agent.

\subsection{Results of ${ }^{13} \mathrm{C}$ NMR analysis}

The raw coal, washed coal before filtration (Before filtration), and coal after filtration (After filtration) were subjected to NMR analysis to identify functional groups and investigate the changes of these functional groups. The coal spectra in Fig. 3 are typical (Xu et al. 2018). Many oxygencontaining functional groups, including alcohol, carboxyl, carbonyl, phenol, ester, and ether were identified in all samples with different intensity (Kim et al. 2013). Other nonoxygen-containing functional groups including aliphatic and aromatic $\mathrm{C}-\mathrm{H}$ groups such as methyl, methylene, and methyne were also identified. This is in line with other studies suggesting low rank coal contains hydroxyl-, methoxy-, and/or methyl-substituted benzene rings, carboxylic acids, and aliphatic linkers like $-\mathrm{CH}_{2} \mathrm{CH}_{2}-$ group (Liu et al. 2013, 2019). The coal sample after filtration has reduced intensities for most functional groups as compared to the 'before filtration' coal sample, including ketones, quinines, aldehydes, aromatics, methylene and methyl carbons.

\subsection{Effects of solvent extraction on coal and solvents}

To investigate the mechanisms of ion removal by coal filtration, PRB coal was solvent-extracted with THF, methanol, or NMP. The total ion removal capacity of the coal (as determined from a filtration cycle without subsequent acid washing) was significantly decreased by solvent extraction, to $26 \%, 23 \%$, and $16 \%$ removal for THF, methanol, and NMP extractions, respectively. 


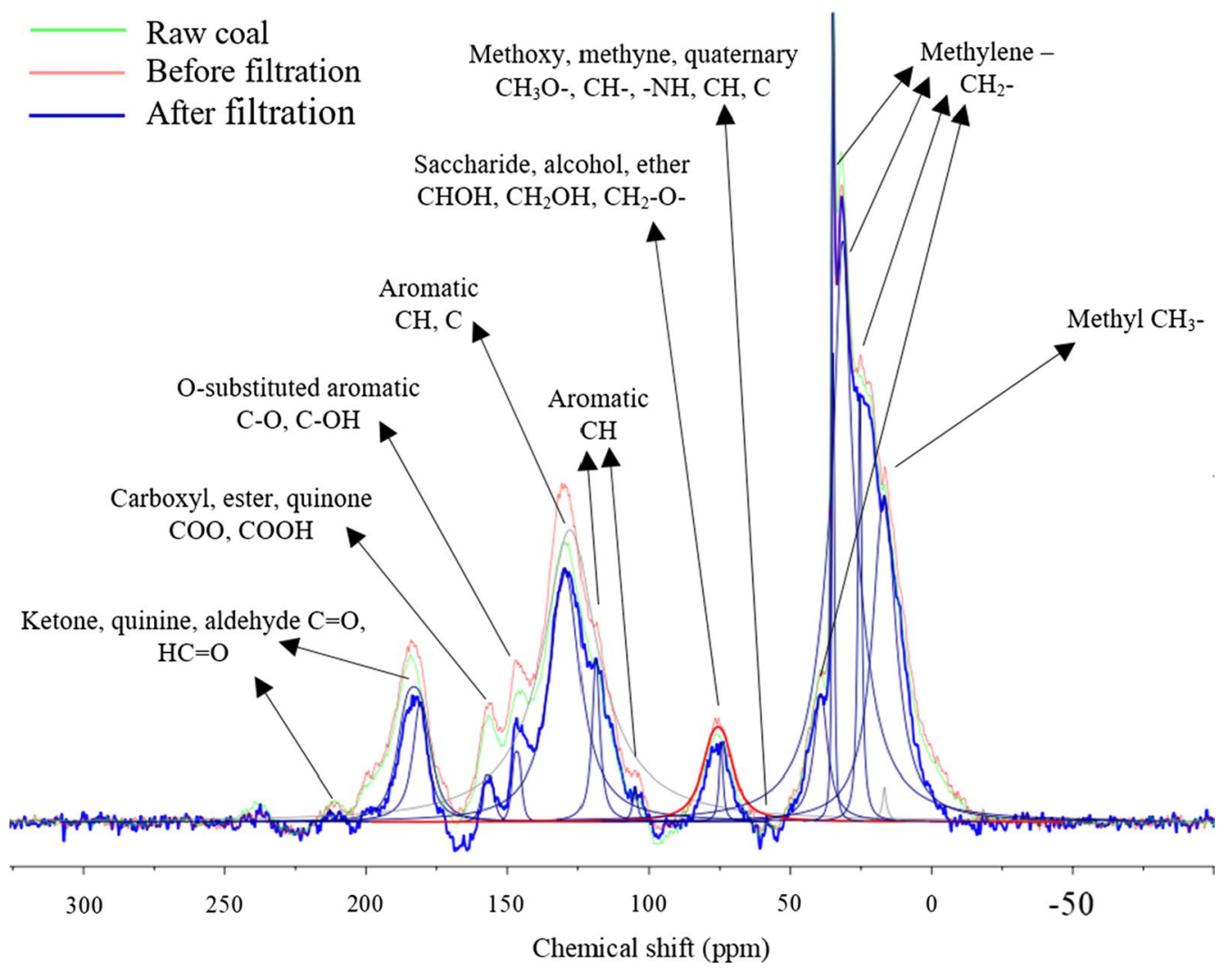

Fig. $3{ }^{13} \mathrm{C}$ NMR analysis of raw coal, washed coal before filtration of produced water and coal after filtration of produced water

Solid coal, both before and after extraction, and liquid solvent after extraction were examined by FTIR analysis. Although there are difficulties in using FTIR to analyze heterogeneous materials like coal with respect to sample preparation, band assignments, and baseline correction (Solomon and Carangelo 1982), a number of functional groups and changes due to solvent extraction were identified in this study. Figure 4 shows the FTIR spectra of coal and liquid from solvent extraction. The peaks were identified according to the literature (Sigma-Aldrich; Xie 2015). The coal structure was modified by solvent extraction to different extents (Fig. 4a). Specifically, coal extracted with NMP exhibited the greatest structural changes with respect to functional groups, followed by methanol and THF. This is consistent with the ion removal capacity where NMP extraction showed the greatest decrease in capacity, followed by methanol and then THF which showed the smallest decrease in ion removal capacity.

The liquid solvents after extraction contained compounds with oxygen- and nitrogen-containing functional groups (Fig. 4b), consistent with the changes in the solid coal functional groups. The intensity of $\mathrm{N}-\mathrm{H}$ stretching for solventextracted coal was significantly reduced, whereas peaks of $\mathrm{N}-\mathrm{H}$ stretching existed in all the liquid extracts. The intensity of the $\mathrm{N}-\mathrm{H}$ peaks of the coal followed the same tendency of ion removal capacity, with less ion removal capacity corresponding to the decreased intensity of the $\mathrm{N}-\mathrm{H}$ peaks. This was also true for other functional groups such carboxyl and phenolic-hydroxyl groups, suggesting that these functional groups may be involved in ion removal. These results are most evident in the NMP treatment where the intensity of these peaks in the extracted coal was significantly reduced while the NMP after extraction had a strong presence of these peaks. NMP has been shown to facilitate the extraction of hydroxyl-containing moieties from bituminous coal (Sun et al. 2014). These results indicate that the extraction of these functional groups significantly impaired the ion removal capacity of the coal, largely related the removal capacity to the number of these oxygen- and nitrogen-containing moieties.

\subsection{Composition of coal extracts}

Volatile and small-molecular compounds in the extracts were characterized by GC/MS to investigate the impact of extractable components on the ion removal. As shown in Fig. 5, the group components detected in the extracts mainly included alkanes, alkenes, arenes, alcohols, phenols, ketones, carboxylic acids, and esters. The relative abundances of oxygencontaining compounds (i.e., alcohols, phenols, ketones, 

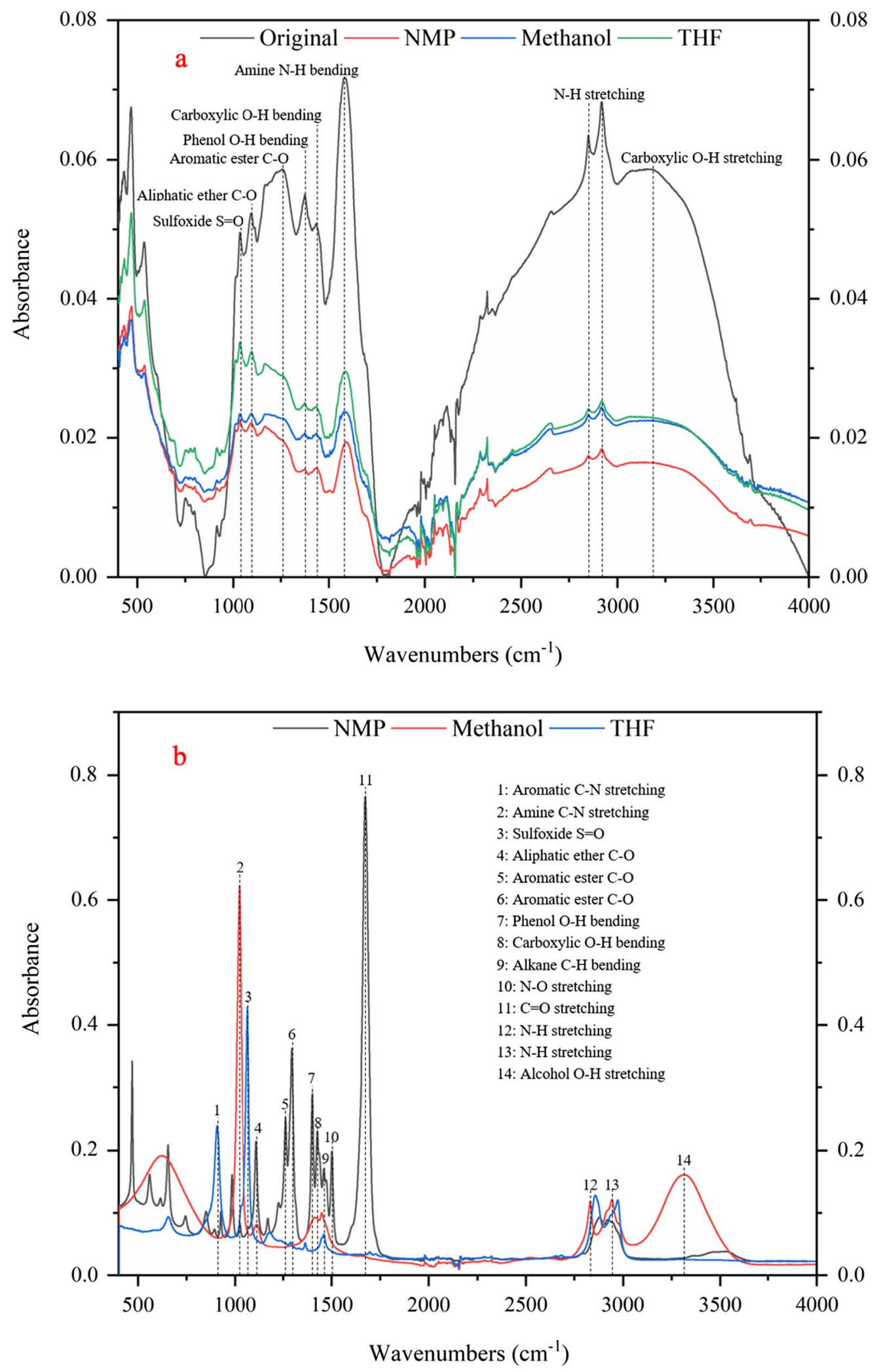

Fig. 4 FTIR spectra of solvent-extracted coal: a Solid coal (Original was coal prior to solvent extraction, NMP, Methanol and THF were extracted coal); b Liquid solvents after extraction 


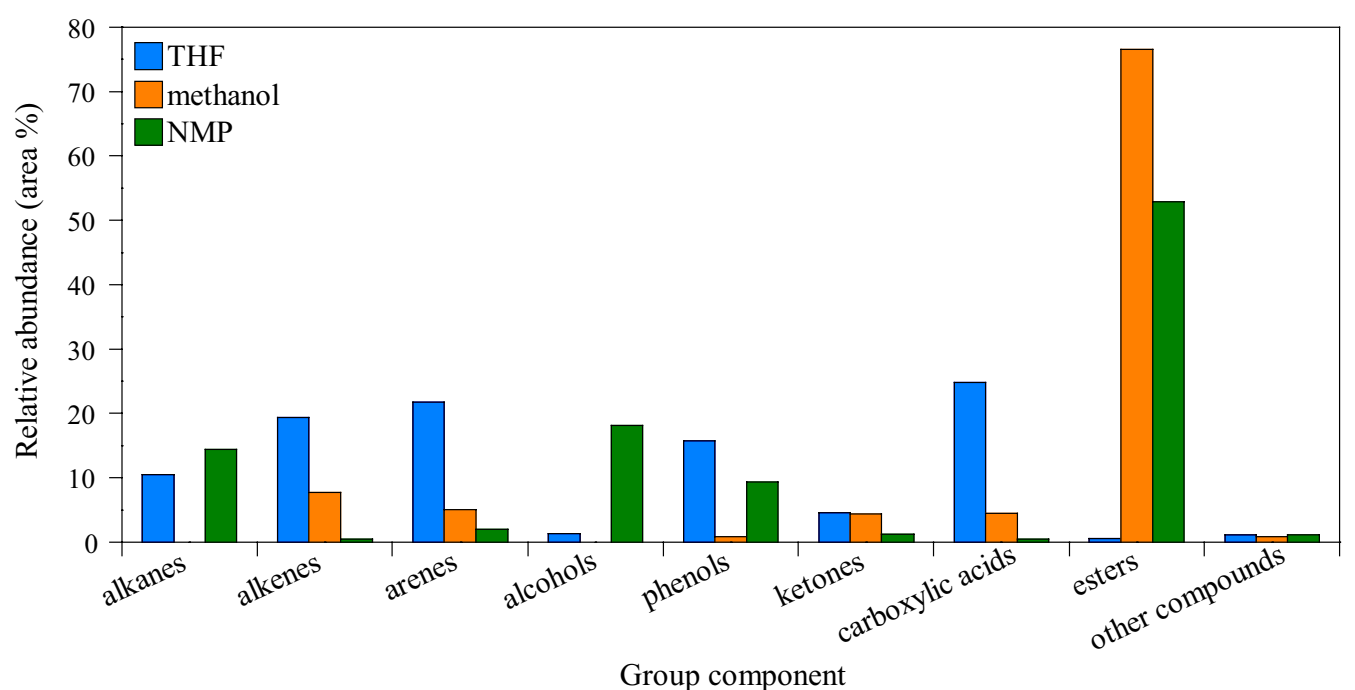

Fig. 5 GC/MS detectable constituents (by group component) in the coal extracts

carboxylic acids, and esters) compared to all extracted compounds were $47.2 \%, 86.4 \%$, and $82.0 \%$ for THF, methanol, and NMP extracts, respectively. Oxygen-containing functional groups, especially carboxyl and hydroxyl, in these compounds may interact with metal cations to form cationbridging linkages (Liu et al. 2016; Mathews and Chaffee 2012), which are beneficial for ion removal. Extraction of these oxygen-containing compounds appears to have significantly reduced the ion removal capacity of the coal.

The detected compounds in the methanol and NMP extracts were dominated by esters with $76.6 \%$ and $52.9 \%$ relative abundance, respectively (Fig. 5), while the hydroxylcontaining compounds (like carboxylic acids, alcohols, and phenols) had a relatively low abundance. As polar solvents, methanol and NMP have proven to be effective for extracting hydroxyl-containing compounds from coals (Liu et al. 2016; Sun et al. 2014). Because GC/MS is only sensitive for volatile and less polar compounds, the GC/MS detectable compounds account for only a fraction of the compounds in the extracts. According to FTIR analysis, NMP extract may also contain many hydroxyl-containing compounds, especially carboxylic acids with low carbon numbers, which were not detected by GC/MS.

\section{Proposed mechanisms of ion removal}

The structure of a coal macromolecule may be visualized as a condensed aromatic carbon-atom lattice surrounded by a typical "fringe" formed by functional side groups. The left panel of Fig. 6 is a hypothetical model of coal structure (Malumbazo 2011). It is a heterogeneous mixture composed of a macromolecule network with varying degrees of cross-linking (Smith et al. 2013). Modified lignin, as well as cellulose and melanoidin-type materials, are considered to be the 'backbone' of this macromolecule network. The cross-linkage of lower rank coal, including subbituminous coal, is dominated by alkyl and aryl ether groups with oxygen functional groups. The chemical heterogeneity of coal decreases from low rank coal to high rank while the aromaticity increases, suggesting that lower rank coals (lignite and subbituminous) have more complex chemical structures than high-rank coals (bituminous coal and anthracite) because the low rank coal contains several distinct classes of constituents (Hofrichter and Fakoussa 2001; Wang et al. 2015). Carboxyl and hydroxyl groups, among others, are the main oxygencontaining functional groups in coal structure which are present in low-rank coal (Xie 2015). Phenolic hydroxyl groups are the main form, but some alcoholic hydroxyl groups also exist.

The removal of cations from produced water by coal filtration is proposed to be through ion exchange (Fig. 6a). The carboxyl and hydroxyl groups may act as ion exchanger sites by exchanging protons $\left(\mathrm{H}^{+}\right)$for other cations $\left(\mathrm{Na}^{+}, \mathrm{K}^{+}\right.$, $\mathrm{Ca}^{2+}, \mathrm{Mg}^{2+}$, etc.) allowing these cations to bind to the negatively charged hydroxyl and carboxyl functional groups. This hypothesis is supported by the $\mathrm{pH}$ measurements of the raw produced water before filtration (6.83) and the water after filtration (as low as 2.28), indicating that protons were released by the coal, presumably due to cation exchange. Additionally, NMR analysis of before and after filtration coal samples also showed significant intensity reduction of carboxyl and hydroxyl groups, further supporting the cation exchange hypothesis. The solvent extraction results provide additional support for the hypothesis. Solvent extraction removed carboxyl and hydroxyl functional groups, as illustrated by the 


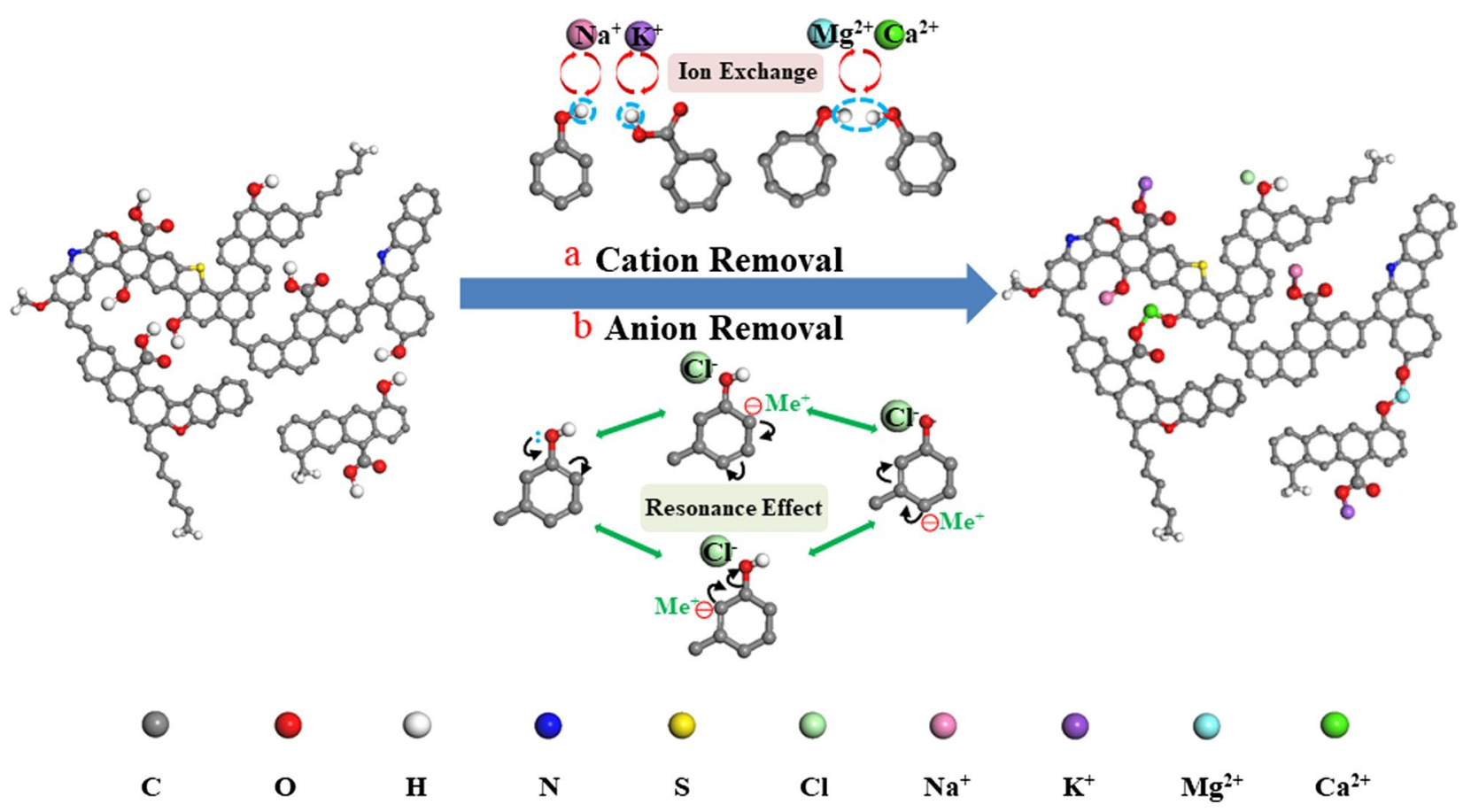

Fig. 6 Proposed mechanism of inorganic ions removal. a Cation exchange; b Resonance effect. The cations (monovalent and divalent) were removed by ion exchange with $\mathrm{H}$-bearing moieties $(-\mathrm{OH}$,

FTIR analyses where the functional groups were removed from the coal and present in the extracts, resulting in significantly impaired ion removal capacity.

Proposed mechanisms for $\mathrm{Cl}^{-}$removal are less clear. One possible removal mechanism is the adsorption of $\mathrm{Cl}^{-}$due to the delocalization of electrons within molecules to form resonance structures (Fig. 6b). This resonance effect or mesomeric effect or electron-donating effect occurs between a lone pair of electrons and a pi bond or two pi bonds next to each other (Dewick 2006). For example, the lone electron pair in the oxygen of the phenolic hydroxyl group may be donated to form a double bond and leave a positive charge. The donation stabilizes the structure of the non-ionized acid such as phenols or derivatives. The donating effect passes the electrons on to the pi bonds along the ring to produce a negative charge of the para- or ortho-carbon in the same aryl ring. These charged molecules could then bond with both negative and positive ions in the produced water to remove them. The resonance effect could be positive or negative. In the positive resonance effect, $-\mathrm{OH},-\mathrm{SH},-\mathrm{OR}$, and $-\mathrm{SR}$ can increase the electron density of the stabilizing ring while $-\mathrm{NO}_{2},-\mathrm{S}=\mathrm{O}$, and $-\mathrm{C}=\mathrm{O}$ could decrease the electron density of the stabilizing ring in the negative resonance effect (Dewick 2006). The removal of these functional groups, as occurred with solvent extraction, would reduce the ion removal capacity of coal.
$\mathrm{COOH}$, etc.). Both cations and anions are proposed to be removed by non-ionized charges induced by resonance effect

Alternatively, the ion removal of any particular ion may not be attributed to any single functional group. Other possible mechanisms to produce charges in coal include changes of electron density by binding alkali metal ions (which are dominant species in produced water) with the functional groups in aromatic structures and electrostatic induction (Xie 2015). In recent decades, ion- $\pi$ interactions have been recognized and found to widely exist as a form of general noncovalent bonding (Dougherty 1996; Ma and Dougherty 1997; Schottel et al. 2008). Ion- $\pi$ interactions happen not only in aromatic systems, but are also well documented in other simple $\pi$ systems such as ethylene and acetylene. Studies show that highly solvated cations can be sequestered by such binding force in aromatic-containing structures (Ma and Dougherty 1997), while anion- $\pi$ interactions happen in electron deficient aromatic systems (Schottel et al. 2008). The anion- $\pi$ interaction combines effects of electrostatic and anion-induced polarization, with the former correlated to permanent quadruple moment, $\mathrm{Q}_{\mathrm{zz}}$ and the latter to molecular polarizability (Quiñonero et al. 2004; Schottel et al. 2008). Aromatic molecules with lower absolute values of $\mathrm{Q}_{\mathrm{zz}}$ could bind to both anion and cation which might account for some of the ion removal in our system (Schottel et al. 2008). The ion $-\pi$ interaction binding energy is estimated to be $20-50 \mathrm{~kJ} / \mathrm{mol}$ which is energetically favorable and is comparable to the binding energy of hydrogen bonds. In the ion- $\pi$ theory, the inductive effect, rather than the resonance 
effect, facilitates binding (Ma and Dougherty 1997; Schottel et al. 2008). Although the mechanisms of anion removal remain hypothetical, based on the results presented herein, coal may be considered a "pseudo-amphoteric" exchanger that has the capability of removing both cations and anions simultaneously and effectively.

\section{Conclusions}

In this study, we have demonstrated that TOC, TSS, and especially TDS can be removed simultaneously from produced water using Powder River Basin subbituminous coal as the treatment material. The material is stable with repetitive filtration-regeneration cycles. More importantly, the coal was shown to have a surprisingly high ion removal capability for produced water containing extremely high dissolved solids ( $>150,000 \mathrm{mg} / \mathrm{L}$ or $15 \%$ ). We propose that the PRB coal is a "pseudo-amphoteric" ion exchange material that could simultaneously remove both positive and negative ions. The analyses strongly support the hypothesis of ion exchange as the mechanism for cation removal whereas the mechanism for anion removal is proposed to be by adsorption through resonance structures induced by delocalization of electrons within coal molecules or through ion- $\pi$ interactions with aromatic clusters. Further work is needed to confirm the anion removal mechanisms. These results may have important ramifications in the reclamation of produced water from the energy production sector.

Supplementary Information The online version contains supplementary material available at https://doi.org/10.1007/s40789-022-00477-1.

Acknowledgements This work was supported by USGS Wyoming Program.

Authors' contributions $\mathrm{ZH}$ : conceptualization, data curation, formal analysis, investigation, methodology, visualization; Writing-original draft/reviewing and editing. FL, MT, YG, XH, AG: data curation, formal analysis, reviewing and editing. DB: formal analysis, supervision, validation; writing-original draft/reviewing and editing. MF: conceptualization, supervision, resources; writing-original draft/reviewing and editing.

Availability of data and materials The data supporting the findings of this study are available within the article and its Supplementary Information files.

\section{Declarations}

Competing interests The authors declare no competing interests.

Open Access This article is licensed under a Creative Commons Attribution 4.0 International License, which permits use, sharing, adaptation, distribution and reproduction in any medium or format, as long as you give appropriate credit to the original author(s) and the source, provide a link to the Creative Commons licence, and indicate if changes were made. The images or other third party material in this article are included in the article's Creative Commons licence, unless indicated otherwise in a credit line to the material. If material is not included in the article's Creative Commons licence and your intended use is not permitted by statutory regulation or exceeds the permitted use, you will need to obtain permission directly from the copyright holder. To view a copy of this licence, visit http://creativecommons.org/licenses/by/4.0/.

\section{References}

Andruleit H, Babies HG, Fleig S, Ladage S, Meßner J, Pein M, Rebscher D, Schauer M, Schmidt S, von Goerne G (2016) Energy Study: Reserves, Resources and Availability of Energy Resources. BGR, Hannover, Germany.

Belbase S, Urynowicz MA, Vance GF, Dangi MB (2013) Passive remediation of coalbed natural gas co-produced water using zeolite. J Environ Manage 131:318-324. https://doi.org/10.1016/j.jenvm an.2013.09.044

Bell EA, Poynor TE, Newhart KB, Regnery J, Coday BD, Cath TY (2017) Produced water treatment using forward osmosis membranes: evaluation of extended-time performance and fouling. $\mathrm{J}$ Membr Sci 525:77-88. https://doi.org/10.1016/j.memsci.2016. 10.032

Dewick PM (2006) Essentials of organic chemistry: for students of pharmacy, medicinal chemistry and biological chemistry. Wiley

Dickhout JM, Moreno J, Biesheuvel P, Boels L, Lammertink RG, de Vos WM (2017) Produced water treatment by membranes: a review from a colloidal perspective. J Colloid Interface Sci 487:523-534. https://doi.org/10.1016/j.memsci.2016.10.032

Dougherty DA (1996) Cation-pi interactions in chemistry and biology: a new view of benzene, Phe, Tyr, and Trp. Science 271:163-168. https://doi.org/10.1126/science.271.5246.163

Duraisamy RT, Beni AH, Henni A (2013) State of the art treatment of produced water. In: Water treatment, IntechOpen

Fakhrul-Razi A, Pendashteh A, Abdullah LC, Biak DRA, Madaeni SS, Abidin ZZ (2009) Review of technologies for oil and gas produced water treatment. J Hazard Mater 170:530-551. https://doi.org/10. 1016/j.jhazmat.2009.05.044

Falbe J, Ahland E, Baron G (1982) Chemical feedstocks from coal

Hackney J, Wiesner MR (1996) Cost assessment of Produced Water Treatment. Retrieved fromhttps://wiesner.cee.duke.edu/sites/ wiesner.cee.duke.edu/files/u18/Produced\%20Water\%20Costs.pdf

Hoekstra AY (2014) Water scarcity challenges to business. Nat Clim Chang 4:318. https://doi.org/10.1038/nclimate2214

Hofrichter M, Fakoussa R (2001) Microbial degradation and modification of coal. Biopolymers 1:393-429

Huang Z, Sednek C, Urynowicz MA, Guo H, Wang Q, Fallgren P, Jin S, Jin Y, Igwe U, Li S (2017) Low carbon renewable natural gas production from coalbeds and implications for carbon capture and storage. Nat Commun 8:568. https://doi.org/10.1038/ s41467-017-00611-7

Huang Z, Fan M, Tian H (2020) Rare earth elements of fly ash from Wyoming's Powder River Basin coal. J Rare Earths 38:219-226. https://doi.org/10.1016/j.jre.2019.05.004

Igunnu ET, Chen GZ (2014) Produced water treatment technologies. Int J Low Carbon Technol 9:157-177. https://doi.org/10.1093/ ijlct/cts049

Jedidi I, Saïdi S, Khemakhem S, Larbot A, Elloumi-Ammar N, Fourati A, Charfi A, Salah AB, Amar RB (2009) Elaboration of new ceramic microfiltration membranes from mineral coal fly ash applied to waste water treatment. J Hazard Mater 172:152-158. https://doi.org/10.1016/j.jhazmat.2009.06.151 
Jiménez S, Micó M, Arnaldos M, Medina F, Contreras S (2018) State of the art of produced water treatment. Chemosphere 192:186208. https://doi.org/10.1016/j.chemosphere.2017.10.139

Kim H-S, Nishiyama Y, Ideta K, Miyawaki J, Matsushita Y, Park J-I, Mochida I, Yoon S-H (2013) Analysis of water in Loy Yang brown coal using solid-state 1H NMR. J Ind Eng Chem 19:1673-1679. https://doi.org/10.1016/j.jiec.2013.02.005

Kim GD, Toy L, Hendren Z, Choi YC, Lesemann M, Buisson H (2017) Oil-field produced water treatment using integrated forward osmosis and membrane distillation process. Proc Water Environ Fed 2017:5297-5305

Kusworo TD, Aryanti N, Utomo DP (2018) Oilfield produced water treatment to clean water using integrated activated carbon-bentonite adsorbent and double stages membrane process. Chem Eng J 347:462-471. https://doi.org/10.1016/j.cej.2018.04.136

Lewińska-Preis L, Szram E, Fabiańska MJ, Nádudvari Á, Misz-Kennan M, Abramowicz A, Kruszewski Ł, Kita A (2021) Selected ions and major and trace elements as contaminants in coal-waste dump water from the Lower and Upper Silesian Coal Basins (Poland). Int J Coal Sci. https://doi.org/10.1007/s40789-021-00421-9

Li L, Whitworth TM, Lee R (2003) Separation of inorganic solutes from oil-field produced water using a compacted bentonite membrane. J Membr Sci 217:215-225. https://doi.org/10.1016/S03767388(03)00138-8

Li G, Guo S, Li F (2010) Treatment of oilfield produced water by anaerobic process coupled with micro-electrolysis. J Environ Sci 22:1875-1882. https://doi.org/10.1016/S1001-0742(09)60333-8

Li X, Zhu X-q, Okuda K, Zhang Z, Ashida R, Yao H, Miura K (2017) Preparation of carbon fibers from low-molecular-weight compounds obtained from low-rank coal and biomass by solvent extraction. New Carbon Mater 32:41-47. https://doi.org/10.1016/ S1872-5805(17)60106-9

Liu F-J, Wei X-Y, Zhu Y, Gui J, Wang Y-G, Fan X, Zhao Y-P, Zong Z-M, Zhao W (2013) Investigation on structural features of Shengli lignite through oxidation under mild conditions. Fuel 109:316-324. https://doi.org/10.1016/j.fuel.2013.01.020

Liu F-J, Wei X-Y, Fan M, Zong Z-M (2016) Separation and structural characterization of the value-added chemicals from mild degradation of lignites: a review. Appl Energy 170:415-436. https://doi. org/10.1016/j.apenergy.2016.02.131

Liu F-J, Gasem KA, Tang M, Goroncy A, He X, Huang Z, Sun K, Fan M (2018) Mild degradation of Powder River Basin sub-bituminous coal in environmentally benign supercritical CO 2-ethanol system to produce valuable high-yield liquid tar. Appl Energy 225:460-470. https://doi.org/10.1016/j.apenergy.2018.05.048

Liu F-J, Zong Z-M, Zhu Y, Wei X-Y, Zhu X-N, Tang M-C, Huang $Z$ (2019) Production of benzenecarboxylic acids from two typical Chinese subbituminous coals by oxidation in aqueous sodium hypochlorite solution and insights into structural characteristics. Fuel 247:386-394. https://doi.org/10.1016/j.fuel.2019.01.037

Ma JC, Dougherty DA (1997) The cation $-\pi$ interaction. Chem Rev 97:1303-1324. https://doi.org/10.1021/cr9603744

Malumbazo N (2011) Chemical and physical structural studies on two inertinite-rich lump coals. PhD Thesis, University of the Witwatersrand. Retrieved from https://www.researchgate.net/profile/ NMalumbazo/publication/301301999_Chemical_and_Physical_ Structural_Studies_on_Two_Inertinite-Rich_Coals/links/57114 51608ae39beb878d753/Chemical-and-Physical-Structural-Studi es-on-Two-Inertinite-Rich-Coals.pdf

Mathews JP, Chaffee AL (2012) The molecular representations of coala review. Fuel 96:1-14. https://doi.org/10.1016/j.fuel.2011.11.025

Mekonnen MM, Hoekstra AY (2016) Four billion people facing severe water scarcity. Sci Adv 2:e1500323. https://doi.org/10.1126/sciadv. 1500323

Munirasu S, Haija MA, Banat F (2016) Use of membrane technology for oil field and refinery produced water treatment-a review.
Process Saf Environ Prot 100:183-202. https://doi.org/10.1016/j. psep.2016.01.010

Nachod FC (2012) Ion exchange: theory and application. Elsevier

Nasiri M, Jafari I, Parniankhoy B (2017) Oil and gas produced water management: a review of treatment technologies, challenges, and opportunities. Chem Eng Commun 204:990-1005. https://doi.org/ 10.1080/00986445.2017.1330747

Otal E, Vilches LF, Moreno N, Querol X, Vale J, Fernández-Pereira C (2005) Application of zeolitised coal fly ashes to the depuration of liquid wastes. Fuel 84:1440-1446. https://doi.org/10.1016/j. fuel.2004.08.030

Oza P, Chaudhuri M (1975) Removal of viruses from water by sorption on coal. Water Res 9:707-712. https://doi.org/10.1016/00431354(75)90061-5

Qi J, Lv J, Bian W, Li J, Liu S (2021) Experimental study on the membrane distillation of highly mineralized mine water. Int J Coal Sci. https://doi.org/10.1007/s40789-021-00432-6

Querol X, Moreno N, Jt U, Alastuey A, Hernández E, Lopez-Soler A, Plana F (2002) Synthesis of zeolites from coal fly ash: an overview. Int J Coal Geol 50:413-423. https://doi.org/10.1016/S01665162(02)00124-6

Quiñonero D, Garau C, Rotger C, Frontera A, Ballester P, Costa A, Deyà PM (2004) Anion- $\pi$ Interactions: do they exist? Angew Chem Int Ed 43:141-141. https://doi.org/10.1002/15213757(20020916)114:18\%3c3539::AID-ANGE3539\%3e3.0. $\mathrm{CO} ; 2-\mathrm{M}$

Ranck JM, Bowman RS, Weeber JL, Katz LE, Sullivan EJ (2005) BTEX removal from produced water using surfactant-modified zeolite. J Environ Eng 131:434-442. https://doi.org/10.1061/ (ASCE)0733-9372(2005)131:3(434)

Rosa N, Widayati S, Monika I (2017) Coal Utilization In The Making Of Activated Carbon For Adsorbed Natural Gas.

Schottel BL, Chifotides HT, Dunbar KR (2008) Anion-pi interactions. Chem Soc Rev 37:68-83

Shahruddin MZ, Othman NH, Alias NH, Ghani SNA (2015) Desalination of produced water using bentonite as pre-treatment and membrane separation as main treatment. Procedia Soc Behav Sci 195:2094-2100. https://doi.org/10.1016/j.sbspro.2015.06.237

Smith KL, Smoot LD, Fletcher TH, Pugmire RJ (2013) The structure and reaction processes of coal. Springer, Berlin

Solomon PR, Carangelo RM (1982) FTIR analaysis of coal. 1. Techniques and determination of hydroxyl concentrations. Fuel 61:663-669. https://doi.org/10.1016/0016-2361(82)90014-X

Song C, Wang T, Pan Y, Qiu J (2006) Preparation of coal-based microfiltration carbon membrane and application in oily wastewater treatment. Sep Purif Technol 51:80-84. https://doi.org/10.1016/j. seppur.2005.12.026

Stoll ZA, Forrestal C, Ren ZJ, Xu P (2015) Shale gas produced water treatment using innovative microbial capacitive desalination cell. J Hazard Mater 283:847-855. https://doi.org/10.1016/j.jhazmat. 2014.10.015

Sun Y, Wang X, Feng T, Yu G, Wang F (2014) Evaluation of coal extraction with supercritical carbon dioxide/1-methyl-2-pyrrolidone mixed solvent. Energy Fuels 28:816-824. https://doi.org/ 10.1021/ef401682g

Veil JA, Markus GP, Deborah E (2004) A white paper describing produced water from production of crude oil,natural gas, and coal bed methane. No. ANL/EA/RP-112631. Argonne National Lab., IL, US.

Vengosh A, Jackson RB, Warner N, Darrah TH, Kondash A (2014) A critical review of the risks to water resources from unconventional shale gas development and hydraulic fracturing in the United States. Environ Sci Technol 48:8334-8348. https://doi.org/10. 1021/es405118y

Wang Y-G, Wei X-Y, Xie R-L, Liu F-J, Li P, Zong Z-M (2015) Structural characterization of typical organic species in Jincheng No. 
15 Anthracite. Energy Fuels 29:595-601. https://doi.org/10.1021/ ef502373p

Wang Q, Guo H, Wang H, Urynowicz MA, Hu A, Yu C-P, Fallgren P, Jin S, Zheng H, Zeng RJ (2019) Enhanced production of secondary biogenic coalbed natural gas from a subbituminous coal treated by hydrogen peroxide and its geochemical and microbiological analyses. Fuel 236:1345-1355. https://doi.org/10.1016/j. fuel.2018.09.114

Woo YC, Chen Y, Tijing LD, Phuntsho S, He T, Choi J-S, Kim S-H, Shon HK (2017) CF4 plasma-modified omniphobic electrospun nanofiber membrane for produced water brine treatment by membrane distillation. J Membr Sci 529:234-242. https://doi.org/10. 1016/j.memsci.2017.01.063

Xie K (2015) Structure and reactivity of coal a survey of selected Chinese coals. Springer, Berlin

Xu B, Kuang D, Liu F, Lu W, Goroncy AK, He T, Gasem K, Fan M (2018) Characterization of Powder River Basin coal pyrolysis with cost-effective and environmentally-friendly composite $\mathrm{NaeFe}$ catalysts in a thermogravimetric analyzer and a fixed-bed reactor.
Int J Hydrog Energy 43:e6935. https://doi.org/10.1016/j.ijhydene. 2018.02.102

Xu B, Cao Q, Kuang D, Gasem KA, Adidharma H, Ding D, Fan M (2020) Kinetics and mechanism of $\mathrm{CO} 2$ gasification of coal catalyzed by $\mathrm{Na} 2 \mathrm{CO} 3, \mathrm{FeCO} 3$ and $\mathrm{Na} 2 \mathrm{CO} 3-\mathrm{FeCO} 3$. J Energy Inst 93:922-933. https://doi.org/10.1016/j.joei.2019.08.004

Zhang K, Li H, Han J, Jiang B, Gao J (2021) Understanding of mineral change mechanisms in coal mine groundwater reservoir and their influences on effluent water quality: a experimental study. Int $\mathbf{J}$ Coal Sci 8:154-167. https://doi.org/10.1007/s40789-020-00368-3

Zhao H, Vance GF, Ganjegunte GK, Urynowicz MA (2008) Use of zeolites for treating natural gas co-produced waters in Wyoming, USA. Desalination 228:263-276. https://doi.org/10.1016/j.desal. 2007.08.014

Zhao H, Vance GF, Urynowicz MA, Gregory RW (2009) Integrated treatment process using a natural Wyoming clinoptilolite for remediating produced waters from coalbed natural gas operations. Appl Clay Sci 42:379-385. https://doi.org/10.1016/j.clay.2008.03.007

\section{Authors and Affiliations}

\section{Zaixing Huang ${ }^{1} \cdot$ Fangjing Liu ${ }^{2} \cdot$ Mingchen Tang ${ }^{2} \cdot$ Yangyan Gao $^{2,3} \cdot$ David M. Bagley $^{2} \cdot$ Xin $\mathrm{He}^{2} \cdot$ Alexander Goroncy ${ }^{4} \cdot$ Maohong Fan ${ }^{1,5}$ (B)}

\section{Maohong Fan}

mfan@uwyo.edu; mfan3@mail.gatech.edu

1 Department of Petroleum Engineering, University of Wyoming, Laramie, WY 82071, USA

2 Departments of Chemical Engineering, University of Wyoming, Laramie, WY 82071, USA
3 Department of Environmental Engineering, Shanxi University, Taiyuan 030001, China

4 Department of Chemistry, University of Wyoming, Laramie, WY 82071, USA

5 School of Civil and Environmental Engineering, Georgia Institute of Technology, Atlanta, GA 30332, USA 